\title{
$\mathbf{X}$
}

\section{NUANCES DO JUVENICÍDIO: TRABALHO NO TRÁFICO DE DROGAS JUSTIFICANDO PRISÕES E MORTES DE PRETOS E POBRES*}

Andréa Pires Rocha

O anúncio do juvenicídio: a morte de Lucas como ícone

Preso desde 2018 pelo porte de 10 gramas de maconha, o jovem negro Lucas Morais de Trindade, 28, morreu no último sábado [04/07/2020] vítima da COVID-19, no presídio de Manhumirim, em Minas Gerais (TAJRA, 2020).

Quem foi Lucas Morais de Trindade? Não sabemos como foi sua vida, onde nasceu, cresceu, em que escola estudou, que tipo de música ouvia, que comida mais gostava, suas experiências profissionais, se tinha filhos. Não analisamos sua história de vida, tão pouco seus processos jurídicos. Mas temos certeza de que era um jovem negro, estava preso por quase dois anos pelo porte de 10 gramas de maconha e morreu dentro de uma prisão de Minas Gerais em decorrência da COVID-19. Essa história, que ganhou repercussão nos últimos meses, nos serve como ícone para a compreensão acerca do juvenicídio e das nuances que nos propomos a refletir.

Mortes de pretos e pobres compõem o genocídio subsidiado historicamente pelo racismo estrutural que delineia a sociedade moderna e seus mecanismos de opressão. Ao observamos a história do Brasil, verificamos que o racismo subsidiou em um primeiro momento a escravização de pessoas negras sequestradas do continente africano, depois perpetuou a condição de exclusão no bojo das relações de trabalho livres (MOURA, 2019; FERNANDES, 1972; GONZÁLEZ, 1984) É, portanto, no contexto do capitalismo periférico e dependente, que para a população negra foram designados os trabalhos precá-

*DOI- 10.29388/978-65-86678-44-4-0-f.251-276 
rios e os piores lugares no exército industrial. Para esta população é dificultado o acesso à educação, saúde, habitação, entre outros direitos. É ainda sobre corpos negros que os aparelhos violentos do Estado têm sua mira apontada.

Essa lógica agrava seus impactos no contexto de crise do capital e recrudescimento da adesão a política econômica neoliberal, que desmonta os sistemas de garantia de direitos ao mesmo tempo em fortalece o modelo de Estado penal, sustentado por discursos ideologizados que tentam deslocar as reais causas das mazelas do próprio modo de produção e convencer que serão resolvidas por meio do fortalecimento da segurança pública e do encarceramento em massa (WACQUANT, 2013; GARLAND, 2014). Mas, as intempéries não param por aí, eis a pandemia da COVID-19 para desnudar o mar de desamparo e vulnerabilidade que os mais pobres enfrentam no país e no mundo. Até a data ${ }^{1}$ em que esse texto se encerra já causou 916.265 mortes no mundo, destas 130.508 foram no Brasil, envolvendo muito mais pessoas negras (somados pretos e pardos), residentes de periferias e aquelas que dependeram de vaga em hospitais colapsados nas diferentes regiões do país.

Torna-se evidente, portanto, que a Questão Social, categoria essencial para a análise das contradições do modo de produção capitalista e de seu contraponto delineado pelo movimento da luta de classes, só pode ser compreendida ao se considerar a relação dialética entre as questões de raça, classe e gênero (ALMEIDA, 2014; GONÇALVES, 2018; ROCHA, 2018). É a partir dessas lentes que situamos a juventude, considerando-a como uma categoria sócio-histórica (ABRAMO, 2005) que, justamente pelo fato de representar a "continuidade da vida social", é submetida a "um forte controle social sobre suas normas e condutas" (FRAGA; IULANELLI, 2003, p. 10). Esse controle se expressa de diferentes formas, sofrendo múltiplas determinações, as quais também delineiam suas vivências singulares e particulares.

Essa ótica nos ajuda a observar que alguns jovens estão no topo das relações sociais hierarquizadas por fazerem parte daqueles que representam o modo de produção capitalista por herdarem capi-

${ }^{1}$ Fonte: Wikipédia COVID-19. Acesso em 12 set. 2020. 
tal, comporem o grupo privilegiado pela ideologia da supremacia branca e pelas relações patriarcais. Em outras palavras: aos jovens homens, brancos e ricos, está reservado a perpetuação do poder. Para outros, há o estabelecimento de esquemas de exigências com vistas ao alcance de lugares na sociedade meritocrática e competitiva, como no caso dos jovens de classe média, que segundo Hart ${ }^{2}$,

[...] estavam muito mais bem preparados para a escola e para lidar
com adultos em posição de autoridade. Eram capazes de falar por si
mesmos e de se valer de argumentos bem estruturados para tirar
conclusões de maneira mais habilidosa. Essa forma elaborada de pen-
sar também os ajudava a fazer planos que exigem passos sucessivos.
Em resumo, estavam mais preparados para o sucesso no estilo de
vida dominante no país que os filhos da classe trabalhadora, indepen-
dentemente do fato de serem negros ou brancos. Com seu estilo de
cuidados paternos, os filhos da classe média estavam sendo treina-
dos para liderar, fosse intencional ou não (HART, 2014, p. 46).

Nesta esteira estão as relações de trabalho e como se constroem mecanismos que visam manter a dominação e suas expressões contemporâneas. A sociedade dividida em classes e racialmente hierarquizada também determinará os rumos da educação, havendo a distinção de um modelo voltado para as elites e outro para classe trabalhadora (PONCE, 1986). Hart também problematiza isso ao apontar que há aqueles que são submetidos ao controle da educação precária e do trabalho mal remunerado, ideologicamente conduzidos para o conformismo em relação a exploração, pois

[...] as crianças pobres e da classe trabalhadora eram treinadas para passar a vida "na base". Os filhos da classe média aprendiam de forma constante e explícita a se posicionar em defesa própria diante da autoridade, ao passo que os das classes inferiores aprendiam a se submeter sem questionamento (HART, 2014, p. 46).

É no contexto da exploração do trabalho que a maioria absoluta dos jovens negros e pobres está inserida. Porém, há ainda aqueles que por conta da condição de vulnerabilidade extrema, encontram alguns espaços para venda de sua força de trabalho na ilegalida-

\footnotetext{
${ }^{2}$ Mesmo considerando que os relatos de Carl Hart se referem ao contexto dos EUA, visualizamos muitas similaridades em relação a realidade dos jovens no Brasil.
} 
de, em particular no tráfico de drogas (FEFFERMAN, 2006; D'ELLIA FILHO, 2015; ROCHA, 2012). É certo que não se trata do trabalho em seu sentido ontológico, mas sim daquele submetido a fragmentação e alienação no interior das relações capitalistas e que de antemão apresentam complexidades por tratar de atividade ilegal que gera acúmulo de capital para aqueles que estão nas pontas mais lucrativas do negócio que envolve as drogas proibidas.

Vale salientarmos que quando nos reportamos genericamente as drogas, falamos de substâncias psicoativas - aquelas que alteram o estado físico, mental e emocional - que acompanham a história da humanidade "com uma luz própria, como quando abrimos a janela até então fechada pelo horizonte, e aparecem as mesmas coisas sob uma perspectiva nova" (ESCOHOTADO, 2004, p. 7), ou seja, em diferentes contextos históricos o uso e a importância dessas substâncias possuem significados particulares. Vale a pena lembrarmos que no bojo da tríade Mercantilismo-Racismo-Colonialismo, a acumulação primitiva acontecia entorno da compra e venda de mercadorias, dentre essas destacamos: os corpos negros coisificados, sequestrados do continente africano e escravizados; e as drogas que compunham o importante comércio de apropriação inglesa dos "monopólios do sal, ópio, bétel e outras mercadorias [que] eram minas inesgotáveis de riqueza" (MARX, 1988, p. 276). ${ }^{3}$

Portanto, o significado das drogas ideologicamente entendido a partir do ponto de vista da proibição é um fenômeno do século XX e decorreu de fatores econômicos, políticos, ideológicos e racistas (RODRIGUES, 2004). No entanto, o fato de terem se tornado proibidas não as retira da condição de mercadorias que satisfazem necessidades humanas, passam por processos de produção, distribuição e circulação que acontecem a partir da exploração de mais-valia (CARNEIRO, 2002; ROCHA, 2012). Desta forma, é consenso entre estudiosos sobre o tema, que é a proibição que inaugura o tráfico de drogas, levando o envolvimento de seres humanos em diferentes cadeias deste lucrativo negócio, alguns como gestores, outros como trabalhadores que tem força de trabalho explorada e, no interior dessas relações é essencial considerarmos que a violência é a cruel mediadora.

\footnotetext{
${ }^{3}$ É interessante que Marx até menciona o potencial da guerra do ópio.
} 
Em pesquisa que desenvolvemos ${ }^{4}$, constatamos que os jovens trabalhadores do tráfico de drogas ganham visibilidade à medida que vivenciam de maneira nua e crua as contradições que vinculam legalidade/ilegalidade. Buscávamos entender as motivações que os mantinham ligados a esse mercado delineado por riscos e violência, e a resposta se justificava no fato da remuneração obtida lhes propiciar satisfações imediatas que vão das mais elementares, como a compra de alimentos para família, a aquelas mais complexas determinadas pela sociedade de consumo e pelo fetiche da mercadoria, como podemos observar no relato abaixo:

Daí veio e tal, eu vi que, tipo assim, não era um futuro promissor,
mas era um futuro com bastante dinheiro, essas coisas, como moto,
carro. Daí eu fui me envolvendo, me envolvendo. Fui pra [...], conse-
gui tudo... O tráfico traz tudo pra você, que você quiser, ele traz.
[Que tipo de coisa?] Ah, sei-lá,... dinheiro, mulher, tudo. Tudo, todo
esse tipo de regalia né. Só que sempre correndo o risco de tá aqui
agora onde que eu tô (C. apud ROCHA, 2012, p. 20).

Essa fala nos leva a reflexão da complexidade das relações que envolvem classe, raça e gênero, pois essa jovem, que era negro, se vê realizado pelas oportunidades financeiras trazidas pelo tráfico de drogas e coloca a mulher como um dos acessos permitidos quando se tem dinheiro, elemento esse que exige aprofundamento mais cuidadoso que não poderemos desenvolver neste texto. De qualquer forma, por mais que seja complexo, visualizamos que na esteira do envolvimento com o tráfico de drogas há subjetividades vinculadas a uma suposta resistência a opressões impostas pelo racismo, pobreza, desigualdade social, entre outros.

Como Hart (2014, p. 46), sequência em sua reflexão, aponta que os jovens pobres, ao contraporem resistência aprendiam fazer

\footnotetext{
${ }^{4}$ Essas compreensões decorreram da experiência na atuação como Assistente Social na execução de medidas socioeducativas em meio aberto e fechado, o que nos trouxe problematizações desenvolvidas em pesquisas. Especial destaque damos a pesquisa realizada no contexto do doutorado que teve como objeto as trajetórias de adolescentes explorados como "mulas" na rota de tráfico internacional proveniente da fronteira Brasil - Paraguai (ROCHA, 2012). Já no estágio de pós doutorado analisamos os argumentos jurídicos e ideológicos que determinavam a manutenção da prisão preventiva de jovens acusados de tráfico de drogas após a realização das Audiências de Custódia em Londrina/PR (ROCHA, 2018).
} 
isso "de maneira encoberta, não declaradamente. Na verdade, a resistência encoberta permeou de tal maneira meus primeiros passos na vida que se tornou tão natural quanto respirar". É nessa resistência encoberta que se inserem os jovens que se recusam a exploração do trabalho formal ou informal aceito moralmente que, na maioria das vezes, oferece remunerações menores que do trabalho no tráfico de drogas. Por outro lado, os próprios jovens sempre apontavam a característica rarefeita e fugaz das realizações decorrentes desta remuneração, apontando o eminente risco de irem presos ou morrerem a qualquer momento.

Os determinantes dessas vivências são imensamente perversos, pois além de serem explorados, os jovens pretos e pobres são os que mais vão presos ou morrem. Não é por acaso que a Organização Internacional do Trabalho (OIT), por meio da Convenção 182 e a Recomendação 190, se refere ao tráfico de entorpecentes como uma das piores formas de trabalho infantil, indicativo reconhecido no Brasil, por meio do Decreto n. 3.597, de 12 de setembro de 2000 (BRASIL, 2000).

Neste sentido, torna-se essencial o debate referente ao juvenicídio cunhado, especialmente, por Valenzuela (2015),

O juvenicídio se inicia com a precarização da vida dos jovens, a ampliação de sua vulnerabilidade econômica e social, o aumento de sua condição de cidadania violada e a diminuição de opções disponíveis para que possam desenvolver projetos viáveis de vida (VALENZUELA, 2015 p. 3-4, tradução nossa).

Afirma ainda que o fenômeno se mostra no cenário neoliberal e "explica algo mais significativo, pois se refere a processos de precarização, vulnerabilidade, estigmatização, criminalização e morte" (VALENZUELA, 2015 p. 11, tradução nossa). Diz respeito aos jovens pretos e pobres que foram consumidos pelo racismo estrutural e pela violação de direitos ao longo de toda sua história de vida, mas que após a prática de delitos são inseridos no contexto da (in)visibilidade perversa (SALLES, 2007).

Em síntese situamos as reflexões sobre a dinâmica que envolve juvenicídio e questão das drogas a partir de algumas implicações, dentre as quais destacamos: a) perpetuação de precárias condições 
de vida dos jovens pobres, especialmente os negros consumidos pelo racismo estrutural; b) a instrumentalidade de legislações proibicionistas para o controle social e racial; c) a proibição como mantenedora do tráfico de drogas e a violência que o acompanha; d) a Guerra às drogas no contexto da necropolítica e do necropoder. Portanto, a morte e o extermino dos jovens é conclusão do processo do juvenicídio que tem suas raízes nas relações estruturais e superestruturais, dentre as quais destacaremos o racismo e os impactos da guerra às drogas via prisões e mortes.

A morte do jovem Lucas, destacada acima, trouxe repercussão e desvelou o quanto a adesão brasileira à guerra às drogas somada ao recrudescimento das implicações do Estado neoliberal de cunho penal, é uma escolha deliberada para manutenção do controle social daqueles que são os mais atingidos pelas expressões da questão social e estão fora de qualquer chance nas relações de trabalho delineadas pela competividade excludente. Ou seja, toda monta de violência, seja ela a partir do controle de corpos em prisões, ou mortes em sentido estrito, se agrava quando olhamos para a população negra, o que nos leva a constatar que na história do Brasil esses fenômenos foram naturalizados historicamente.

\section{Primeira nuance: o racismo como substrato}

Primeiro levaram os negros Mas não me importei com isso,

Eu não era negro. (BERTOLD BRETCH)

Se pretos e pobres sãos os que mais morrem e vão presos, é inegável que o racismo é o principal substrato do juvenicídio. Compreendemos a questão racial no contexto das relações estruturais centradas na categoria trabalho e superestruturais, que se dão na esfera da ideologia, subsidiando a manutenção da ordem capitalista e sua sociabilidade burguesa. Desta forma concordamos com Munanga $(2003$, p. 3) que mesmo sendo constatado que não há distinções biológicas entre os seres humanos, o conceito de raça é um demarcador social "carregado de ideologia", que em uma sociedade racista não 
pode ser ignorado. A partir deste entendimento, constatamos que a racialização da humanidade serviu e ainda serve para a perpetuação de sistemas de hierarquização voltados para exploração, dominação e opressão em diferentes fases da história e modos de produção.

Ao nos remetermos novamente as análises de Marx (1988) sobre o processo de acumulação primitiva, veremos que

O sistema colonial fez amadurecer como plantas de estufa o comércio a e navegação. [...] foram alavancas poderosas da concentração de capital. As manufaturas em expansão, as colônias asseguravam mercado de escoamento e uma acumulação potenciada por meio do monopólio de mercado. $O$ tesouro apressado fora da Europa diretamente por pilhagem, escravização e assassinato refluía à metrópole e transformava-se em capital (MARX, 1988 p. 277).

De forma direta o pensador ressalta o quanto o sistema colonial cristão foi imensamente violento e lucrativo. Portanto, é essencial a consideração de que o Colonialismo e a exploração da força de trabalho de pessoas negras escravizadas foram alicerces para a consolidação do Capitalismo como modo de produção (WILLIAMS, 2012). Nessa esteira é importante mencionarmos que a sociedade Moderna, desenhada especialmente pelo pensamento iluminista se fundamentou a partir de elementos racistas que defendiam a superioridade branca europeia e inferioridade negra africana (SOMET, 2016).

$\mathrm{Na}$ esfera da economia política destacamos o Liberalismo, que coloca a propriedade privada como centro das relações humanas, justificando-a a partir de uma ideia de liberdade que não abrange todos. Esse pensamento será o substrato político-ideológico das primeiras revoluções burguesas ${ }^{5}$. No século XIX o racismo se cristaliza por meio de uma ciência rodeada de argumentos refutáveis, deixando de ser particularidade da sociedade escravocrata, perpetuando-se nas relações sociais pós-escravidão.

Destacamos a influência da obra "Ensaio sobre a desigualdade das raças humanas" do diplomata francês Joseph Arthur de Gobine-

\footnotetext{
${ }^{5}$ Um dos principais marcos é a Declaração dos Direitos do Homem e do Cidadão francesa, de 1789, que em tese demonstra a superação do Absolutismo, mas mantém a hierarquização social e racial. A grande prova dessa contradição é a persistência do colonialismo e da escravidão negra que tem como principal contraponto a revolução do Haiti (JAMES, 2010; LOSUR DO, 2006).
} 
au, publicada entre 1853 e 1855, na qual se explica que a morte de uma civilização decorre da degeneração provocada pela mestiçagem. Nesta lógica, o desenvolvimento civilizatório se dá a partir da conquista de uma nação sobre a outra, possibilitando o crescimento da riqueza e do comércio, no entanto a superioridade da raça branca pode cair em degeneração se muito misturada (MUNANGA, 1999; DIWAN, 2018). A biologia também é utilizada para explicar a hierarquização social, fundando-se especialmente na teoria evolucionista que teve como marco a publicação da obra "A origem das espécies" de Darwin em 1859, trazendo a premissa de que

[...] a luta pela vida, na qual só os mais bem adaptados sobrevive, a permanente competição e a conclusão de que os mais bem "equipados" biologicamente têm maiores chances de se perpetuar na natureza [...] Tais ideais encontrarão eco nas teorias econômicas e sociais que justificarão o comportamento humano em sociedade (DIWAN, 2018, p. 30).

Assim se alicerçam o Higienismo, a Eugenia e o Darwnismo Social, elaborações teóricas que influenciarão legislações e políticas públicas no Brasil a medida em que se vinculam as esferas médicolegal, perpetuando o biopoder em diferentes aspectos das relações sociais. Diwan (2018) destaca que o ideal republicano trouxe necessidade de se definir qual seria o típico brasileiro em consonância com a proposta da eugenia ${ }^{6}$, que colocava a possibilidade do estabelecimento de um "novo tempo", no qual haveria a melhoria da raça brasileira. Em tempos republicanos o racismo é oficializado e materializado por meio de políticas de embranquecimento (MUNANGA, 1999). Há que se destacar que essa leitura de sociedade foi redesenhada por Gilberto Freyre, quando traz a miscigenação para o terreno da negação do racismo, falseando a existência de uma democracia racial no Brasil (FERNANDES,1972; NASCIMENTO, 2016; MOURA, 2019).

\footnotetext{
${ }^{6}$ O principal expoente da Eugenia no país foi o médico Renato Kehl que, em 1917 afirma tra tar-se da "ciência do aperfeiçoamento moral e físico da espécie humana [...] é a ciência da boa geração. Ela não visa, como parecerá a muitos, unicamente proteger a humanidade do cogumelar de gentes feias" (DIWAN, 2018, p. 96).
} 
Outra tradição teórica do século XIX que não podemos deixar de considerar nas reflexões sobre o lugar do racismo na criminalização de jovens negros e pobres é o pensamento Antropológico criminal cunhado por Cesáre Lombroso, que inaugura a Escola Positiva do Direito Penal. A obra mais conhecida é "O Homem Delinquente", publicada em 1876, na qual traça diversos elementos que servem como características físicas e culturais para se identificar um criminoso. No entanto, nos chama atenção a obra que em tradução livre tem como título "O homem branco e o homem negro: leituras sobre a origem e variedade de raças humanas" , lançada em 1892, por se centrar especificamente na criminalização dos negros, determinando-os como inferiores e passíveis de crimes,

[...] se as variedades humanas existiram desde o início, ou gradualmente, conforme tentamos demonstrar, foram obtidos porque os negroides, os mais imperfeitos, foram transformados nos mais perfeitos, os brancos, deixando no espaço, um monumento eterno de sua origem, um casulo vivo, desses tipo antigo, eles se apresentam a nós com profundas e evidentes desigualdades (LOMBROSO, 2004, p. 53, tradução livre).

Foram muitos os intelectuais brasileiros que aderiam ao pensamento racista impetrado em países europeus e nos Estados Unidos da América. Destacaremos Raymundo Nina Rodrigues (2011), que em 1894 já defendia a distinção entre as raças no Brasil e a propensão dos negros cometerem delitos. Ao levantar o questionamento "[...] pode-se conceder que a consciência do direito e do dever que tem essas raças inferiores, seja a mesma que possui a raça branca civilizada?" (RODRIGUES, 2011, p. 43), responde que as diferenças exigem que as penas sejam diferentes, impetrando maior rigor para os negros.

Mariza Corrêa (2001) ao desenvolver uma análise aprofundada sobre o pensamento de Nina Rodrigues, aponta a defesa de uma lógica de flexibilização criminal para um grupo social e o enrijecimento para aqueles considerados criminosos natos. A preocupação de fundo se vinculava ao Positivismo em busca de uma suposta ordem

\footnotetext{
${ }^{7}$ Do original: "Luomo bianco e luomo di colore: letture su l'origine e la varietà delle raz ze umane" (LOMBROSO, 2004)
} 
social. O desenho da função do perito era feito a partir de uma "definição por oposição, num primeiro momento, separando a medicina judiciária (avaliar o dano) da medicina clínica (restaurar a saúde) e da higiene (prevenir a moléstia)" (CORRÊA, 2001, p. 99). Envolvendo em uma só proposta o pensamento antropológico criminal, o higienismo e a eugenia, o que resultará em resquícios até hoje observados nas decisões dos Sistemas de Segurança e Justiça, que reproduzem a perpetuação do racismo estrutural ${ }^{8}$.

Portanto, nos interessa agora a particularidade da política de drogas brasileira consolidada nos primeiros anos do século XX. Saad (2018) destaca, como importante expoente, José Rodrigues da Costa Dória ${ }^{9}$, formado em medicina no ano de 1882, que segundo a autora, também era entusiasta das teorias de Lombroso. A pesquisadora explica que além da defesa de que as análises médico-legais deveriam reconhecer criminosos e vagabundos a partir das características físicas, Dória abordava outros temas complementares, os quais envolviam,

[...] substâncias alteradoras da consciência, degeneração e impulsos criminais, diferenciação entre os sexos, entre outros, revelam um homem conservador preocupado com a moral, o desenvolvimento da boa raça e a manutenção da ordem (SAAD, 2018, p. 38).

Este pensamento influenciará a política de drogas brasileira, primeiro, por defender que os vícios estavam vinculados a degradação humana, segundo por racializar os supostos problemas decorrentes da maconha ${ }^{10}$. Inicialmente havia a aceitação dos venenos chics

\footnotetext{
${ }^{8}$ Há um conjunto ideológico voltado a possibilitar que decisões da "justiça" fossem resultantes de uma seletividade penal determinada, em primeira instância pela questão racial. Nos anos finais do século XIX, pouco depois da abolição da escravatura, legislações brasileiras colocam em prática a síntese deste conjunto de pensamentos subsidiados pelo racismo. O Primeiro Código Criminal da República de 1890, traz em seus artigos elementos que criminalizam de forma direta pessoas negras, pobres (FLAUZINA, 2006; MALAGUTTI BATISTA, 2006; ROCHA, 2018) e coloca a questão das drogas como monopólio do poder médico.

${ }^{9}$ A autora refere que em sua trajetória acadêmica e profissional, nunca mencionou Nina Rodrigues, no entanto, havia muitas semelhanças na análise de ambos.

${ }^{10}$ Aqui cabe destacarmos dois elementos interessantes apresentados por LIMA (2009), o primeiro se refere ao fato de que em 1822 um dos Códigos de Condutas do Rio de Janeiro, apresentava a criminalização da maconha a partir de motivações racistas. O segundo diz respeito ao fato de o Brasil ter regulamentado o uso controlado da maconha em 1932, ou seja,
} 
que compunham o cotidiano das classes mais abastadas, mas quando o uso desses produtos se expande para os sujeitos considerados degradados, essas drogas também entram na mira da proibição (PASSETTI, 1991). Por outro lado, Saad (2018) destaca que a maconha sempre foi associada aos negros, como símbolo de degradação a priori $^{11}$.

É nesta esteira que se relaciona a questão das drogas com a questão racial, criando-se a identidade da política de drogas brasileira, sem deixar de lado a influência da ideologia proibicionista que era hegemônica e protagonizadas pelo EUA, que também se desenha a partir de substratos racistas, tendo como fundamento inicial o Puritanismo. Em suma, o histórico das legislações brasileiras voltadas a questão das drogas revela a efetivação da complacência com os brancos e pessoas de classe sociais elevadas, vistas como usuários/doentes, em contraponto ao rigor penal impetrado contra os negros e pobres, estigmatizados essencialmente como criminosos e traficantes.

\section{Segunda nuance: a necropolítica e o necropoder da guerra às drogas, suas prisões e mortes}

Jovem, preto, novo, pequeno Falcão fica na laje de plantão no sereno

Drogas, armas, sem futuro Moleque cheio de ódio invisível no escuro, puro É fácil vir aqui me mandar matar, difícil é dar uma chance a vida Não vai ser a solução mandar blindar O menino foi pra vida bandida.

(MV BILL)

O proibicionismo é a politização do puritanismo, enquanto a guerra às drogas é a instrumentalização mais nefasta e racista do controle proibicionista ${ }^{12}$. Michelle Alexander (2017), ao desvendar conexões entre racismo e guerra às drogas, demonstra que a declara-

\footnotetext{
"cinco anos antes do Marijuana Tax Act (1937)", atendendo os encaminhamentos das Conferências de 1925 e 1931, realizadas pela Liga das Nações.

${ }^{11}$ Dória representou em 1915 o Brasil e apresentou o estudo sobre maconha totalmente contaminado pelo racismo no II Congresso Científico Pan-Americano em Washington. É curioso mencionarmos que o Brasil foi vanguarda na criminalização da maconha.
} 
ção da guerra feita por Nixon em 1973, foi uma retórica que se construiu sobre legislações proibicionistas já existentes, ocupando o lugar das legislações segregacionistas. Wacquant (2013) ao analisar o mesmo contexto, traz para o debate elementos voltados a crise econômica, que também se mostraram na busca de estratégias de controle social e racial no contexto do agravamento das condições de vida decorrente das crises do capitalismo e, consequentemente, da implantação neoliberal centrada no desmonte das políticas sociais.

A interface entre racismo estrutural e guerra às drogas no bojo do Estado neoliberal de cunho penal é o terreno fértil para dinamização da opressão e violência sobre comunidades inteiras. No Brasil esses elementos se constituem a partir da construção de um sistema penal "republicano" fundado no racismo estrutural, que tem como público predileto negros e pobres, somado a adesão da retórica da guerra que se perpetua desde o final da década de 1970 e a implantação do neoliberalismo a partir da década de 1990 (VALOIS, 2017; BOITEUX, 2006; ROCHA, 2018).

Essencial se faz observarmos o quanto essa interface é detentora de uma necropolítica, subjugando a "vida ao poder da morte", somada ao necropoder, elementos que explicam a sociabilidade contemporânea, na qual,

[...] armas de fogo são implantadas no interesse da destruição máxima de pessoas e da criação de "mundos de morte", formas novas e únicas da existência social, nas quais vastas populações são submetidas a condições de vida que lhes conferem o status de "mortosvivos" (MBEMBE, 2016, p. 146).

Achille Mbembe demonstra as reconfigurações do colonialismo, do fascismo, do racismo, que se dão a partir dos mesmos fundamentos, porém em novas bases. Aponta que sob a ditadura do necropoder "as fronteiras entre resistência e suicídio, sacrifício e redenção,

\footnotetext{
12 Aqui cabe um adendo, pois um dos elementos que mais auxiliaram o fortalecimento do imperialismo dos EUA foi a própria questão das drogas, que naquele país tem determinantes ideológicos assentados no Puritanismo, mas que ao longo do tempo, torna-se essencialmente um elemento político nas relações internacionais, visando a imposição do poder imperialista em favorecimento das próprias relações capitalistas internacionais (DELMANTO, 2010).
} 
martírio e liberdade desaparecem" (MBEMBE, 2016, p. 146). Visualizamos todas essas expressões no contexto do juvenicídio que recai sobre os jovens que trabalham no tráfico de drogas, os quais são submetidos ao controle penal e aos riscos constantes impetrados pela violência dos sistemas de segurança e dos agentes do narcotráfico, que em suas expressões mais graves levam a morte.

\section{Prisões}

Nosso governo é tão justo que construiu mais presídios que escolas (509E)

Há, portanto, uma capilaridade no interior do sistema de segurança e justiça amparado pelo racismo e pela seletividade penal (ZAFARONI, 2014; BARATTA, 1987) que se utiliza de legislações ${ }^{13}$ fundadas no proibicionismo e sua guerra às drogas, das quais os alvos prioritários são os jovens negros. Os resultados dessas conexões são catastróficos e se mostram no aumento progressivo do encarceramento em massa que no Brasil, no período de 1990 a 2016, foi da ordem de 707\% (INFOPEN, 2017, p. 9).

Dentre as 726.712 pessoas privadas de liberdade em 2016 (em regimes fechado e aberto ${ }^{14}$ ), $94 \%$ são do sexo masculino, 64\% são negros, 55\% tem entre 18 e 29 anos de idade, ou seja, falar que as cadeias estão repletas de jovens pretos e pobres não é mero recurso discursivo. Em relação aos delitos, $28 \%$ se referem a acusação de tráfico de drogas e $37 \%$ correspondem a soma dos delitos de roubo/furto, ou seja, somados estes três delitos correspondem a $65 \%$ dos casos de pessoas presas já sentenciadas ou aguardando julgamento (BRASIL, 2017).

\footnotetext{
${ }^{13} \mathrm{O}$ direito compõe o rol de elementos superestruturais e tem como principal função manter as relações centradas na propriedade privada e exploração de mais valia. Além disso, vale a pena destacarmos que os sistemas punitivos são construídos em resposta às necessidades das relações de produção (RUSCHE; KIRCHHEIMER, 2004).

${ }^{14}$ Neste número absoluto se inserem presos provisórios (40\%), sentenciados a regime fechado (38\%), que somados constituem 573.009 pessoas. Além disso, envolvem os regimes semiaberto (15\%) e aberto (6\%), somados somam 153.703 pessoas. Contudo, não incluem as penas restritivas de direitos, que também são formas de controle. Buscamos estatísticas recentes sobre os índices de penas restritivas de direitos, no entanto não conseguimos nenhum dado confiável.
} 
No que se refere aos adolescentes em medidas socioeducativas, em 2015, 96\% dos adolescentes em restrição ou privação de liberdade era formada pelo sexo masculino e $61,03 \%$ eram pretos e pardos. Os atos infracionais de maior recorrência também são roubo $37 \%$ e tráfico $27 \%$. Ou seja, esses delitos têm a ver com elementos resultantes das expressões da questão social, pois crimes contra a propriedade privada e crimes referentes ao tráfico de drogas, são aqueles cometidos por jovens que historicamente foram submetidos a violações de direitos desde a infância. Isso evidencia que mesmo com avanços no que se refere a positivação de direitos, "nos extremos permanecem a punição e o controle sociopenal, que continuam criminalizando a pobreza e julgando que os adolescentes pobres constituem marginais em potencial" (OLIVEIRA E SILVA, 211, p. 228).

Em pesquisa que analisamos os determinantes jurídicos e sociais que subsidiam à manutenção das prisões preventivas (provisórias) de jovens entre 18 e 29 anos de idade por tráfico de drogas após a realização das Audiências de Custódia em Londrina/PR (ROCHA, 2018). Dentre os processos analisados, apresentaremos um caso exemplar da (in)justiça da guerra às drogas. Trata-se da situação de jovem de 23 anos flagrado com 23 gramas de cocaína que estava em companhia de um adolescente de 15 anos, segue um trecho do Termo de Audiência de Custódia,

\begin{abstract}
Apesar de não possuir antecedentes criminais, sendo considerado primário, o apresentado encontra-se desempregado, demonstrativo do risco de reiteração delitiva. Ademais, o crime de tráfico de droga denota-se de extrema gravidade, eis que é motivo de cometimento de outros delitos graves, como crimes contra o patrimônio e contra a vida. Assim é real periculosidade de manutenção de sua liberdade, eis que é concreta a chance de voltar a delinquir. Imprescindível, assim, a prisão preventiva como forma de garantir a ordem pública. [julgado 188 dias depois e condenado a pena restritiva de direitos: PSC e multa) (TERMO DE AUDIÊNCIA DE CUSTÓDIA 3).
\end{abstract}

É evidente que o magistrado criminaliza a pobreza, afirmando que o fato de o jovem estar desempregado o levaria a delinquir novamente. Os argumentos evidenciam a lógica que refletimos até agora, pois demarcam que o trabalho no tráfico de drogas é uma decorrên- 
cia da falta de emprego, ou seja, precariedade de condições materiais. Porém, a resolução proposta é contrária a garantia de direitos, optando-se por mantê-lo privado de liberdade preventivamente por 188 dias, sendo liberado após julgamento que o condenou a pena restritiva de direitos.

A grande maioria dos processos analisados teve desfechos semelhantes, o que nos levou a constatar que as prisões provisórias empreendem o controle intermitente destes jovens. Retirando-os de circulação por algum tempo e enquanto estão presos entram nas estatísticas do cárcere e são retirados das estatísticas que denunciam o desemprego, a precariedade da política de educação e profissionalização, a ausência de espaços propiciadores de lazer e cultura, e inúmeras outras violações de direitos sociais.

Há ainda que se considerar situações de mortes ocorridas dentro das prisões, frutos de violência entre grupos, mas agora há a questão da pandemia tornando mais grave este fenômeno. $O$ site do Departamento Penitenciário Nacional (BRASIL, 2020) apresenta que até a data de 19.924 pessoas privadas de liberdade foram contagiadas e destas 105 morreram em decorrência da COVID-19 no interior das instituições penais.

Além deste crescente número de contágios, movimentos de luta pelo desencarceramento tem denunciado nas redes sociais o recrudescimento das violações de direitos humanos nas prisões, que vão da proibição de visitas em nome da "proteção" contra o COVID19, a restrição de água, ausência de materiais de higiene e a ocorrência de torturas deliberadas.

\section{Mortes}

Falo pro mano, pra que não morra, e também não mate (RACIONAIS $M C^{\prime}$ )

É inegável que o fato de apontarmos que o índice de mortes violentas no Brasil é próprio de países em guerra não é uma mera analogia, pois de fato estamos em guerra. A violência letal decorrente de operações policiais ou de acerto de contas no interior do tráfico de drogas são as formas mais contemporâneas do genocídio da juventude preta e pobre. O Atlas da Violência (BRASIL, 2020) demons- 
tra que, segundo o Sistema de Informação sobre Mortalidade, no ano de 2018 houve 57.956 homicídios no Brasil, destes 30.873, ou seja, $53,3 \%$, eram jovens o que significa uma taxa de 60,4 homicídios por 100 mil habitantes. Em relação ao total de pessoas que foram vítimas de homicídios $75,7 \%$ é formada por negros, somando-se os pretos e pardos. Outro dado estarrecedor é que do total geral 4.519 mulheres foram assassinadas no Brasil e destas $68 \%$ eram negras. O documento destaca a questão da guerra de grupos pertencentes as facções criminosas como um dos vetores destes índices.

O Anuário Brasileiro da Segurança Pública (FBSP, 2019), lançado em setembro de 2019, com dados de 2018, traz informações sobre as mortes violentas no país, como sistematizamos abaixo:

$\begin{array}{ccc}\begin{array}{c}\text { QUADRO I - MORTES VIOLENTAS NO BRASIL } \\ \text { Ano }\end{array} & \begin{array}{c}\text { Mortes Violentas Intencionais (MVI) - } \\ \text { geral }\end{array} & \begin{array}{c}\text { Morte Decorrente de Interven- } \\ \text { ção Policial }\end{array} \\ & 64.078 & \text { (em serviço e fora de serviço) } \\ 2017 & 57.358 & 6.179 \\ 2018 & & 6.220 \\ & -10,8 \% & +20 \%\end{array}$

Fonte: Sistematização da autora a partir dos dados apresentados no Anuário Brasileiro da Segurança Pública (BRASIL, 2019)

Podemos observar que houve no país uma queda de $10,8 \%$ nos índices gerais de mortes violentas intencionais, porém as mortes decorrentes de intervenção policial cresceram em $20 \%$. No documento há uma análise que divide os homicídios brasileiros em cinco grupos: 1) mortes internas ao mundo do crime e suas redes próximas, 75-80\%; 2)mortes ocorridas na guerra entre as polícias e o mundo do crime, 11,45\%; 3) feminicídios, 6-8\%; 4) latrocínios, 3,3\%; 5) homicídios de LGBT, ativistas e defensores de direitos, jornalistas e políticos, 1\% (BRASIL, 2019). Essas informações revelam pontos reflexivos essenciais para a compreensão do juvenicídio no Brasil, pois, em relação ao grupo um, os analistas referem que é

[...] composto por operadores baixos dos mercados ilegais (drogas, armas, veículos roubados, contrabando etc.). São comumente, portanto, jovens negros, de sexo masculino, com escolaridade defasada, moradores de favelas e periferias urbanas, frequentemente com pas- 
sagens pela justiça criminal. São as mortes internas às redes do mundo do crime (FBSP, 2019, p. 31).

No que se refere ao grupo dois, os dados revelam "a soma das vítimas da letalidade policial e de policiais mortos [...] Nessa guerra, em média morre um policial para cada 18 mortes cometidas pela polícia" (FBSP, 2019, p. 31). Constatamos que nas duas pontas da violência decorrente da guerra às drogas os jovens negros e pobres estão em maior condição de vulnerabilidade, a medida em que são as principais vítimas das mortes ocasionadas pela violência institucional, mas também estão entre os principais mortos das guerras internas ao próprio mundo do crime. Neste ponto se estabelece um dado muito cruel, pois cerca de 75 a $80 \%$ dos homicídios ocorridos no Brasil, são protagonizados pelos próprios jovens vinculados ao tráfico de drogas e/ou a outros delitos violentos. É o resultado da guerra e suas guerras na composição do juvenicídio.

\section{Pelo fim do juvenicídio: as lições da dona Teresa, uma mãe em luta!}

As breves reflexões desenvolvidas neste texto a partir de algumas nuances do juvenicídio, nos permitem considerar que, de fato, este é um fenômeno composto por múltiplas determinações, como muito bem nos ensina Marx em seu método. Lembremos que desde o processo de sua consolidação como Estado republicano, o Brasil tem se apoiado na hierarquização racial e em disparidades sociais, econômicas e políticas. O racismo estrutural, a adesão à ideologia proibicionista, a implementação da Guerra às Drogas, os desmontes neoliberais, o fortalecimento do Estado penal, somados à seletividade do sistema de segurança e punitivo, confirmam que o encarceramento em massa de negros, pobres e jovens é uma escolha que tende a aumentar.

Por outro lado, não há a mínima demonstração de preocupação em relação a realidade vivenciada por esses jovens, que trabalham em um mercado imensamente lucrativo e perigoso, pois as regras são manejadas por meio da violência, levando muitas vezes a morte. As guerras internas do tráfico de drogas e as ações dos órgãos 
de segurança, colocam a vida desses jovens em risco. Quando escapam da morte, são submetidos às prisões.

Há saídas? D. Maria Teresa dos Santos, principal referência do Grupo de Amigos e Familiares de Pessoas em Privação de Liberdade (GAFPPL), mulher negra, guerreira, mãe de jovem preso, militante orgânica pelo desencarceramento, nos traz importantes lições em um vídeo que circulou no mês de agosto de 2020, no qual nos propõe duas importantes pautas. A primeira é:

Legaliza essa porcaria, começa vender lá na farmácia. Na [nomes de farmácias] Droga sei lá o que. Que eu quero ver os grandes empresários se matarem como os nossos estão se matando por um dinheiro que nem é deles. Porque eles vendem droga, morrem por causa da droga, são presos por causa da droga, mas nenhuma de nós tem o dinheiro da droga par apagar o advogado deles. [...] Legaliza, vai fumar quem quiser fumar, porque ninguém é obrigado a fazer nada. Porque proibido já tá todo mundo fumando.

Esse é um ponto (DONA TERESA, 2020).

A fala mostra a síntese da luta antiproibicionista, assentada no rompimento com o pacto belicista da guerra, por meio de um redesenho da política de drogas, centrada nas pessoas, não nas drogas e nas penas. Concordamos que o fim do proibicionismo e o estabelecimento de uma nova política onde o Estado possa ser o principal gerenciador da produção, distribuição e circulação das drogas para uso medicinal e recreativo, é o antídoto para os efeitos nefastos deste necropoder. Junto disso, a lógica do tráfico de drogas e a violência que o acompanha também poderão ser superadas. Neste terreno também visualizamos possibilidades mediante a implementação de política propositiva em ações que de fato poderiam prevenir o uso abusivo de substâncias psicoativas e que tenham o cuidado de seres humanos como foco, não prisões e mortes. Outra pauta levantada por D. Teresa é,

Outro ponto que é muito questionado é o "nenhuma vaga a mais". "D. Tereza de loucura é essa?" o presídio está lotado, tem que construir mais presídio. Esparramar essas cadeias. "meu marido está dormindo no chão tem um ano". O meu filho tem dois anos que está dormindo na beirada do boi". Quando cria uma vaga, cria 10 pessoas 
para ocupar aquela vaga. [...] $\mathrm{O}$ dinheiro de construir cadeia tem que ser gasto na primeira infância.

É da luta pelo desencarceramento que D. Teresa trata, enfatizando que o investimento em prisões deveria ser revertido para educação, saúde, lazer. Há no Brasil campanha puxada pela Pastoral Carcerária em conjunto com movimentos de mães de jovens que foram mortos ou estão presos, que gira entorno da Agenda Nacional do Desencarceramento que, dentre suas pautas, defende a suspensão do investimento em novas unidades, pois apesar da superlotação das instituições penais, sabe-se que o aumento de vagas acompanhará, proporcionalmente o aumento do encarceramento em uma sociedade neoliberal de cunho penal. Essas pautas, são revolucionárias e ganharão mais força se empreendidas a partir do que Angela Davis (2018, p. 34) chama de "interseccionalidade de lutas" que tenham como meta final, a superação da ordem do capital.

\section{Referências}

ABRAMO, H. W. Condição juvenil no Brasil contemporâneo. In: ABRAMO, H. W.; BRANCO, P. P. M. (Org.) Retratos da juventude brasileira: análises de uma pesquisa nacional. São Paulo: Fundação Perseu Abramo, Instituto Cidadania, 2005.

ALEXANDER, M. A nova segregação: racismo e encarceramento em massa. Tradução de Pedro Davoglio. São Paulo: Boitempo, 2017.

ALMEIDA, M. da S. Desumanização da população negra: genocídio como princípio tácito do capitalismo. Em Pauta: teoria social e realidade contemporânea - Revista da FSS/UERJ, Rio de Janeiro, n. 34, v. 12, p. 131-154, 20 semestre de 2014.

BARATTA, A. O paradigma do gênero: da questão criminal à questão humana. In: CAMPOS, C. H. (Org). Criminologia e feminismo. Porto Alegre: Editora Sulina, 1999.

BOITEUX, L. A nova lei antidrogas e o aumento da pena do delito de tráfico de entorpecentes. Boletim IBCCrim, São Paulo, ano 14, n. 167, p. 8-9, out. 2006. 
BRASIL. Levantamento Nacional de Informações Penitenciárias - INFOPEN Atualização - Junho de 2016. Brasília: Ministério da Justiça e Segurança Pública, Departamento Penitenciário Nacional, 2017.

. Painel de monitoramento de casos suspeitos e confirmados de COVID-19 nos sistemas prisionais do mundo. Brasília: DEPEN, 2020. Disponível em: <https://app.powerbi.com/view?r=eyJrljoiYThhMjk5YjgtZWQwYS00ODIkLTg4NDgtZTFhMTgzYmQ2MGVIliwidCI6ImViMDkwNDIwLTQONGMtNDNmNy05MWYyLTRiOGRhNmJmZThIMSJ9>. Acesso em: 08 set. 2020.

. Secretaria Geral da Presidência da República. Secretaria Nacional de Juventude. Mapa do Encarceramento: jovens do Brasil. Brasília: Presidência da República, 2015.

. Instituto de Pesquisa Econômica Aplicada - IPEA. Atlas da Violência. Brasília: IPEA, Fórum Brasileiro de Segurança Pública (FBSP), 2020.

. Decreto №. 3.597, de 12 de setembro de 2000. Promulga Convenção 182 e a Recomendação 190 da Organização Internacional do Trabalho (OIT) sobre a proibição das piores formas de trabalho infantil e a ação imediata para sua eliminação, concluídas em Genebra, em 17 de junho de 1999. Diário Oficial da União, Poder Executivo, Brasília, DF, 13 set. 2000. p. 4. Disponível em: <http://www.planalto.gov.br/ccivil_03/decreto/D3597.htm>. Acesso em: 10 ago. 2020.

CARNEIRO, H. S. As necessidades humanas e o proibicionismo das drogas no século XX. Outubro, São Paulo, v. 6, p. 115-128, 2002. CORRÊA, M. As ilusões da liberdade: a Escola Nina Rodrigues e a Antropologia no Brasil. São Paulo: Editora Universidade São Francisco, 2001.

D'ELIA FILHO, O. Z. Indignos de vida: a forma jurídica da política de extermínio de inimigos na cidade do Rio de Janeiro. Rio de Janeiro: Revan, 2015.

DAVIS, A. A liberdade é uma luta constante. Organização Franck Rarat; Tradução Heci Regina Candiani. São Paulo: Boitempo, 2018. 
DELMANTO, J. Imperialismo e proibicionismo: raízes e interesses da proibição das drogas e da suposta guerra ao tráfico. 2010. Disponível em: <http://www.neip.info/index.php/content/view/1459.html>. Acesso em: 15 mar. 2012.

DIWAN, P. Raça pura: uma história da eugenia no Brasil e no mundo. São Paulo: Contexto, 2018.

DONA TERESA, MÃE DE PRESO, NEGRA E PERIFÉRICA, DÁ A LETRA SOBRE A GUERRA ÀS DROGAS, Ponte Jornalismo. 2020. Disponível em: $<$ https://www.youtube.com/watch?v=2ScXsvTqn5Y>. Acesso em: 08 set. 2020.

ESCOHOTADO, A. História elementar das drogas. Lisboa: Antígona, 2004.

EURICO, M. C. Questão racial e Serviço Social: uma reflexão sobre o racismo institucional e o trabalho do assistente Social. 2011. Dissertação (Mestrado em Serviço Social). Pontifícia Universidade Católica de São Paulo, 2011.

FEFFERMAN, M. Vidas arriscadas: o cotidiano dos jovens trabalhadores do tráfico. Petrópolis: Vozes, 2006.

FERNANDES, F. O negro no mundo dos brancos. São Paulo: Difusão Europeia do Livro, 1972.

FERRUGEM, D. Guerra às drogas e a manutenção da hierarquia racial. Belo Horizonte: Letramento, 2019.

FLAUZINA, A. L. P. Corpo negro caído no chão: o sistema penal e o projeto genocida do Estado brasileiro. Rio de Janeiro: Contraponto, 2008.

FÓRUM BRASILEIRO DE SEGURANÇA PÚBLICA - FBSP. Anuário Brasileiro de Segurança Pública. Ano 13, São Paulo: FBSP, 2019.

FRAGA, P. C. P.; LUNIANELLI, J. A. S. (Org.). Jovens em tempo real. Rio de Janeiro: DPA, 2003.

GARLAND, D. A cultura do controle: crime e ordem social na sociedade contemporânea. Rio de Janeiro: Revan, 2014. 
GIORGI, A. De. A miséria governada através do sistema penal. Rio de Janeiro: Revan; ICC, 2013

GONÇALVES, R. Quando a questão racial é o nó da questão social. Katálysis, Florianópolis, v. 21, n. 3, p. 514-522, set./dez. 2018.

GONZÁLEZ, L. Racismo e sexismo na cultura brasileira. Revista Ciências Sociais Hoje, ANPOCS, p. 223-244, 1984.

HART, C. Um preço muito alto: a jornada de um neurocientista que desavia nossa visão sobre drogas. Trad. Clovis Marques. Rio de Janeiro: Zahar, 2014.

JAMES, C. L. R. Os jacobinos negros: Toussant L'Ouverture e a revolução de São Domingos. São Paulo: Boitempo, 2010.

LIMA, R. de C. C. Uma história das drogas e do seu proibicionismo transnacional: relações Brasil-Estados Unidos e os organismos internacionais. 2009. 365f. Tese (Doutorado em Serviço Social). Programa de Pós-Graduação em Serviço Social, Universidade Federal do Rio de Janeiro, Rio de Janeiro, 2009.

LOMBROSO, C. L'uomo bianco e l'uomo di colore, letture su l'origine e la varieta' delle razze umane. 2a. ed. Seconda edizione con

l'aggiunta di 7 Appendici e con incisioni. Firenze Torino Roma, Fratelli Bocca, Librai di S.M. il Re d'Italia, 1892. 1a ed. eletronica del 8 settembre 2004.

LOSURDO, D. Contra-história do liberalismo. Aparecida: Ideias e Letras, 2006.

MALAGUTI BATISTA, V. O medo na cidade do Rio de Janeiro: dois tempos de uma história. Rio de Janeiro: Revan, 2014.

MARX, Carl. 0 capital: crítica da economia política. v. 1 e 2. São Paulo: Nova Cultural, 1988.

MBEMBE, A. Necropolítica: biopoder soberania, estado de exceção, política da morte. Arte \& Ensaios - Revista do PPGAV-EBA-UFRJ, n. 32, p. 123-151, dezembro, 2016

MOURA, C. Sociologia do negro brasileiro. 2. ed. São Paulo: Perspectiva, 2019. 
MUNANGA, K. Rediscutindo a mestiçagem no Brasil: identidade nacional versus identidade negra. Petrópolis: Vozes, 1999.

. Uma abordagem conceitual das noções de raça, racismo, identidade e etnia. Palestra proferida no 3 o Seminário Nacional Relações Raciais e Educação - PENESB, Niterói, UFF, em 05 nov. 2003. (mimeo).

NASCIMENTO, A. O genocídio do negro brasileiro: processo de um racismo mascarado. 3. ed. São Paulo: Perspectivas, 2016.

OLIVEIRA E SILVA, M. L. Entre proteção e punição: o controle sociopenal dos adolescentes. São Paulo: Editora UNIFESP, 2011.

PASSETTI, E. Das fumeries ao narcotráfico. São Paulo: EDUC, 1991. PONCE, A. Educação e luta de classes. Tradução: José Severo de Camargo Pereira. 6. ed. São Paulo: Cortez, Autores Associados, 1986. ROCHA, A. P. Prisão provisória de jovens pelo crime de tráfico de drogas após a realização das audiências de custódia em Londrina/ PR (relatório final de pesquisa de estágio de pós-doutoramento). Rio de Janeiro: Programa de Pós-Graduação em Serviço Social da ESSUFRJ, 2018.

. Trajetórias de adolescentes apreendidos como "mulas" do transporte de drogas na região da fronteira (Paraná) Brasil - Paraguai: exploração de força de trabalho e criminalização da pobreza. 2012. 396 f. Tese (Doutorado em Serviço Social). Faculdade de Ciências Humanas e Sociais, Universidade Estadual Paulista "Júlio de Mesquita Filho", Franca/SP, 2012.

RODRIGUES, R. N. As raças humanas e a responsabilidade penal no Brasil. [online]. Rio de Janeiro: Centro Edelstein de Pesquisa Social, 2011. Disponível em <http://books.scielo.org>. Acesso em: 02 set. 2020.

RODRIGUES, T. M. S. Política e drogas nas Américas. São Paulo: EDUC; FAPESP, 2004.

RUSCHE, G.; KIRCHHEIMER, O. Punição e estrutura social. 2. ed. Rio de Janeiro: Revan, 2004. 
SAAD, L. Fumo de negro. Salvador: edUFBA, 2019.

SALES, M. A. (In)visibilidade perversa: adolescentes infratores como metáfora da violência. São Paulo: Cortez, 2007.

SOMET, Y. A África e a Filosofia. Revista Sísifo, Feira de Santana, v. 1, n. 4, novembro, 2016. Disponível em: <www.revistasisifo.com>. Acesso em: 11 jan. 2019.

TAJRA, A. Jovem negro de 28 anos preso com $10 \mathrm{~g}$ de maconha morre de COVID-19 em MG. Portal UOL, Segurança Pública, 10 de julho de 2020. Disponível em: <https://noticias.uol.com.br/cotidiano/ultimasnoticias/2020/07/10/jovem-negro-de-28-anos-preso-com-10g-demaconha-morre-de-covid-19-em-mg.htm?cmpid=copiaecola $>$. Acesso em: 02 set. 2020.

VALENZUELA, J. M. (Coord.). Juvenidicio: Ayotzinapa y las vidas precarias em America Latina y España. Barcelona: Ned Ediciones; Guadalajara: ITESO; Tijuana: El Colegio de la Frontera Norte, 2015.

VALOIS, L. C. $O$ direito penal da guerra às drogas. 2. ed. 1. reimp. Belo Horizonte: D'placido, 2017.

WACQUANT, L. Punir os Pobres: a nova gestão da miséria nos Estados Unidos. Tradução de Sérgio Lamarão. 3ạ ed., revista e ampliada. Rio de Janeiro: Revan, 2013.

WILLIAMS, E. Capitalismo e escravidão. Trad. Denise Bottmann; Prefácio Rafael de Bivar Marques. São Paulo: Companhia das Letras, 2012.

ZAFFARONI, E. O inimigo do direito penal. Rio de Janeiro: Revan, 2014. 